\title{
First Trimester Uterine Rupture: A Case Report on a Patient with Unsuspected Müllerian Duct Anomaly
}

\author{
Rosales H. Diego 1,2, García B. Julián ${ }^{1,2}$, Valdes R. Enrique ${ }^{1,3^{*}}$, Cartallier Otone ${ }^{1,2}$, \\ Rojas L. Daniel ${ }^{1,2}$, Valdes M. Enrique', Montero S. Juan², Eliash D. Hector ${ }^{2}$ \\ ${ }^{1}$ Universidad Andres Bello, Santiago, Chile \\ ${ }^{2}$ Hospital El Pino, San Bernardo, Chile \\ ${ }^{3}$ Universidad de Chile, Santiago, Chile \\ Email: *e.valdes.r.63@gmail.com
}

How to cite this paper: Diego, R.H., Julián, G.B., Enrique, V.R., Otone, C., Daniel, R.L., Enrique, V.M., Juan, M.S. and Hector, E.D. (2021) First Trimester Uterine Rupture: A Case Report on a Patient with Unsuspected Müllerian Duct Anomaly. Open Journal of Obstetrics and Gynecology, 11, 917-921. https://doi.org/10.4236/ojog.2021.117086

Received: April 29, 2021

Accepted: July 25, 2021

Published: July 28, 2021

Copyright $\odot 2021$ by author(s) and Scientific Research Publishing Inc. This work is licensed under the Creative Commons Attribution International License (CC BY 4.0).

http://creativecommons.org/licenses/by/4.0/

(c) (i) Open Access

\begin{abstract}
Introduction: Mullerian malformations are a group of malformations that result from an alteration of embryonic development. Most cases are asymptomatic, however, in pregnant patients it has been associated with recurrent abortion or premature delivery. Case presentation: $12+2$ weeks pregnant woman consulted for abdominal pain, vomiting and fever. During the study, a transvaginal ultrasound was performed, where two endometric cavities and a pregnancy in the right horn were observed. The evolution of the patient was torpid, reaching hypovolemic shock, resolved by an emergency laparotomy where the rupture of the right horn was found. Discussion: The bicornuate uterus is the consequence of a partial fusion of the paramesonephric ducts during the fetal development, resulting in two functional uterine horns. Patients with bicornuate uterus may be asymptomatic, a uterine rupture is a rare but potentially severe complication of the bicornuate uterus and is usually presented during first and second trimester. Conclusions: Pregnancy with Mullerian anomalies often has preterm delivery, IUGR and malpresentation, and even more severe complication as uterine ruptura, so, requires proper counselling and close monitoring during antenatal period.
\end{abstract}

\section{Keywords}

Uterine Rupture, Müllerian Duct Anomalies, Pregnancy Complications

\section{Introduction}

Mullerian malformations are a group of malformations that result from an alte- 
ration of embryonic development, specifically, the Mullerian or paramesonephric ducts affecting the uterine tubes, uterus, cervix and $2 / 3$ of the vagina [1]. The prevalence of these malformations varies in the literature, differentiating between the general population $(3 \%-4 \%)$ and the infertile population $(5 \%-10 \%)$, reaching its highest prevalence in the population with fetal death in the first-second trimester or premature delivery $(10 \%-25 \%)$ [2].

Most of the cases in the Mullerian malformations are asymptomatic, however, they can cause gynecological symptoms such as pelvic pain, abnormal uterine bleeding, hematometer or hematocolpos, infection of the genital tract [3]. In pregnant patients, it has been associated with recurrent abortion or premature delivery, intrauterine growth restriction, fetal deformities, placental insertion abnormalities, cervical insufficiency, rudimentary horn rupture [4].

Rupture of the gravid uterus is a rare obstetric catastrophe with high mortality and morbidity. It is more common in multigravida or in scarred uterus and usually occurs at labor [5]. Bicornuate uterus specifically is associated with adversely reproductive outcomes and very rarely can lead to rupture uterus during the pregnancy.

\section{Case Report}

A healthy primigravid white woman presented at $12+2$ weeks of gestation with acute lower abdominal pain, vomit, and fever. Vitals were normal upon arrival. On clinical examination, the patient presented soft but slight tenderness on lower abdomen. High white blood cell count $\left(15.500 \mathrm{cells} / \mathrm{mm}^{3}\right)$ and elevated C-reactive protein $(27.4 \mathrm{mg} / \mathrm{dL})$ levels were found.

Urinalysis was suggestive of urinary tract infection, so the patient was admitted, and received intravenous antibiotics for a suspected acute pyelonephritis. Routine transvaginal ultrasound imaging revealed two separate echogenic endometrial cavities, with a 12-week pregnancy on the right horn (Figure 1).

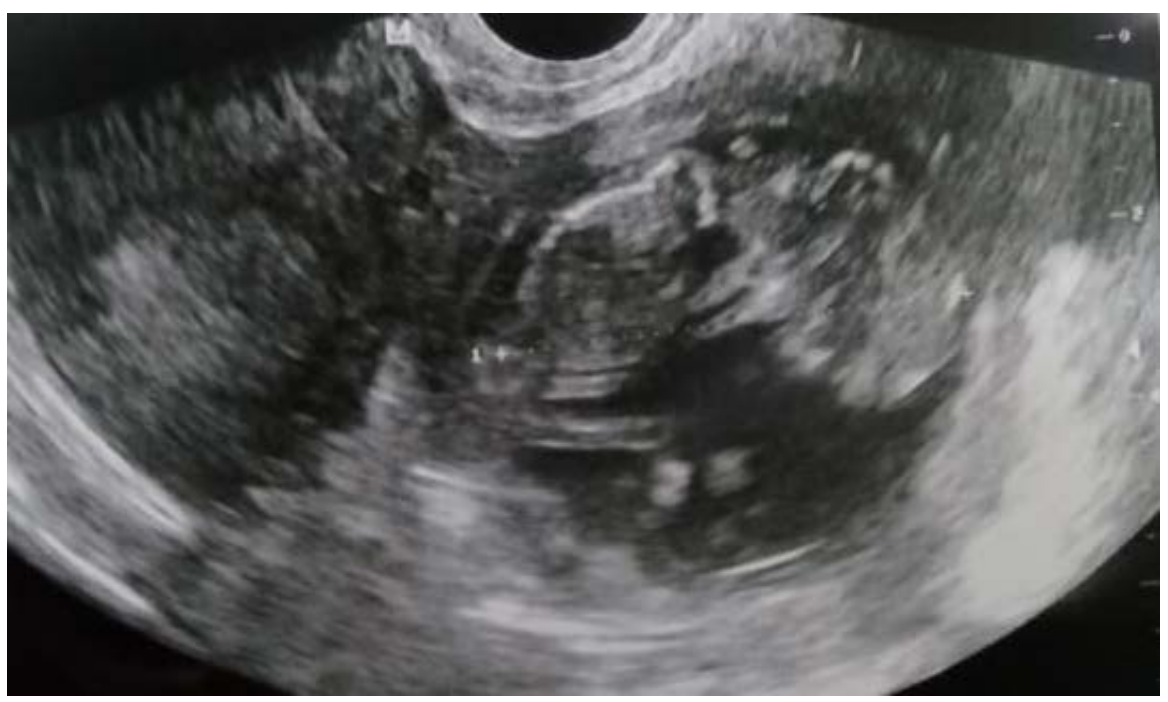

Figure 1. Transvaginal ultrasound showing a 12-week fetus on the right uterine horn. 
After the first day of admission, our patient presented progressive abdominal pain. On clinical examination she looked pale, with a blood pressure of 98/49 $\mathrm{mmHg}$, and a heart rate of $112 \mathrm{bpm}$. Abdominal tenderness and rigidity were found. US evaluation revealed free abdominal fluid, and the absence of the fetus inside of the uterus.

An emergency laparotomy was performed, and a hemoperitoneum of approximately 1.5 liters of blood, along both fetus and placenta outside of the uterus were found due to a right uterine horn rupture (Figure 2). The abdomen was cleared of clots, and the right horn of the uterus was removed. The patient required 2 units of packed red blood cells postoperatively and was discharged in stable condition; further pregnancies were discouraged. Weekly postoperative control was maintained, with recovery of hematocrit and hemoglobin, associated with sexual abstinence and initiation of the contraceptive method.

\section{Discussion}

Pregnancy in the presence of Müllerian duct malformations always requires close monitoring. Due to the increased risk of preterm birth and intrauterine fetal restriction, the role of ultrasound in this control is key, associated with the measurement of cervical length and the estimation of fetal weight, respectively. However, we must not forget the less frequent but more serious complications, such as uterine rupture, which should be suspected when consulting with acute abdominal pain or metrorrhagia in the first trimester.

There are different types of classification of malformations, the most widely

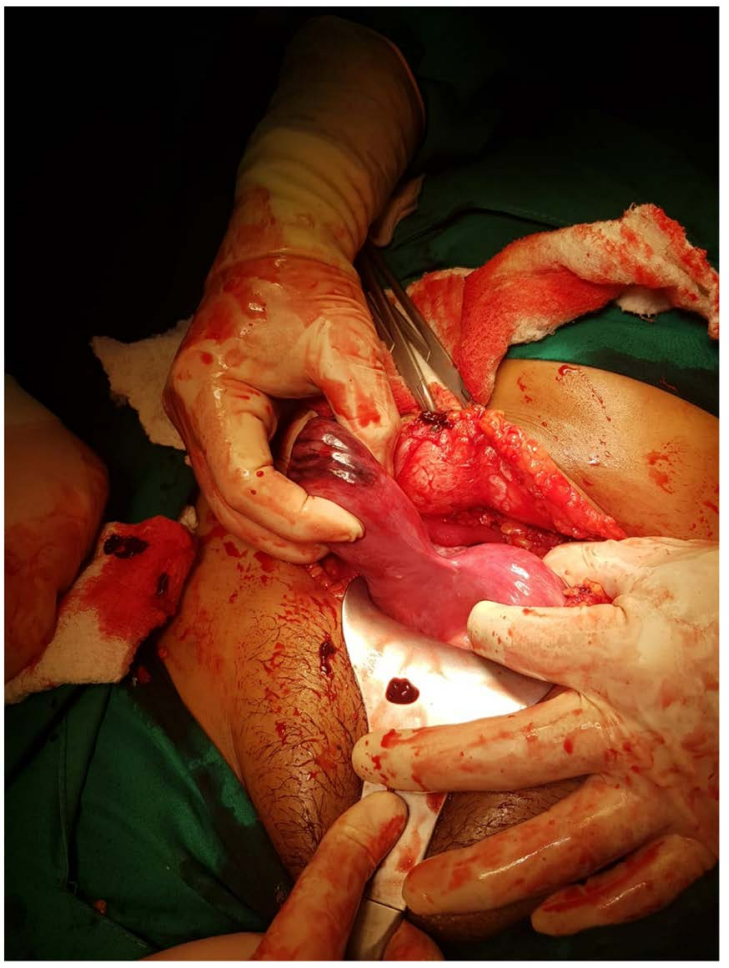

Figure 2. Intraoperative photography showing a right uterine horn rupture. 
used and accepted is the classification system of the American Society for Reproductive Medicine (ASRM), in which Mullerian agenesis or hypoplasia, unicornuate uterus, bidelphic uterus, bicornuate uterus, uterus are differentiated. septate, arcuate uterus, and diethylstibestrol-related anomies [6].

The bicornuate uterus is the consequence of a partial fusion of the paramesonephric ducts during the fetal development, resulting in two functional uterine horns. Patients with bicornuate uterus may be asymptomatic, but are usually associated with miscarriage, malpresentation, cervical insufficiency, fetal grow restriction, infertility, premature birth, and stillbirth. Uterine rupture is a rare but potentially severe complication of the bicornuate uterus and is usually presented during first and second trimester. Asymptomatic primigravids patients are at special risk of this complication. Diagnosis is typically based on 2D US findings, but a hysterosalpingogography or an MRI is needed to stablish a definitive diagnosis.

In the case presented, a patient is evaluated at the end of the first trimester, with acute abdominal pain, which as a finding in the ultrasound evaluated in the emergency room, a bicornuate uterus was evidenced for the first time, because at the beginning there was no the antecedent to suspect a complication of that condition. However, after persisting with the symptoms and a clumsy evolution leading to hypovolemic shock, the diagnosis of uterine rupture is made, which is corroborated and resolved by an exploratory laparotomy.

A similar case was presented in the international journal of surgery case reports (Ashraf F. Hefny) in the Arab Emirates, a patient undergoing a 9-week pregnancy presenting a clinic identical to our patient, however, in this case, the ultrasound was observed abundant free liquid, so the surgical revision was performed earlier.

When all possible complications are clear, it is important to inform the population about these at the preconception moment, to make an early diagnosis in the first trimester if it has not been done before and in case of having a previous uterine scar, advise against pregnancy at least for one year [7]-[13].

\section{Conclusion}

The bicornuate uterus is an infrequent condition, associated with complications during pregnancy, the most frequent being premature delivery and growth restriction. A rare complication, but with great morbidity and mortality, is uterine rupture, which should be suspected, especially in patients with prior knowledge of this condition, in cases of acute abdominal pain or metrorrhagia in the first trimester.

\section{Conflicts of Interest}

The authors declare no conflicts of interest regarding the publication of this paper.

\section{References}

[1] Raj, N., et al. (2019) An Observational Study of Effect of Mullerian Anomalies on 
Pregnancy. International Journal of Reproduction, Contraception, Obstetrics and Gynecology, 8, 115-1161.

[2] Hefny, A.F., Kunhivalappil, F.A., Nambiar, R. and Bashir, M.O. (2015) A Rare Case of First-Trimester Ruptured Bicornuate Uterus in a Primigravida. International Journal of Surgery Case Reports, 14, 98-100. https://doi.org/10.1016/j.ijscr.2015.07.019

[3] Venetis, C.A., Papadopoulos, S.P., Campo, R., Gordts, S., Tarlatzis, B.C. and Grimbizis, G.F. (2014) Clinical Implication of Congenital Uterine Anomalies: A Meta-Analisis of Comparative Studies. Reproductive BioMedicine, 29, 665-683. https://doi.org/10.1016/j.rbmo.2014.09.006

[4] Ravasia, D., Brain, P.H. andPollard, J.F. (1999) Incidence of Uterine Rupture among Women with Müllerian Duct Anomalies Who Attempt Vaginal Birth after Cesarean Delivery. American Journal of Obstetrics and Gynecology, 181, 877-881. https://doi.org/10.1016/S0002-9378(99)70318-2

[5] Beguería, R. (2009) Malformaciones Müllerianas: Clasificación, diagnóstico y manejo. Ginecología y obstetricia clínica, 10, 165-169.

[6] Chandler, T.M., Machan, L.S., Cooperberg, P.L., Harris, A.C. and Chang, S.D. (2009) Müllerian Duct Anomalies: From Diagnosis to Intervention. The British Journal of Radiology, 82, 1034-1042. https://doi.org/10.1259/bjr/99354802

[7] Aguilar, C., García-Herrero, S., Medrano, J.V. and Melo, M.A.B. (2008) Pronóstico reproductivo de las malformaciones müllerianas. Progresos de Obstetricia y Ginecología, 51, 721-736. https://doi.org/10.1016/S0304-5013(08)76314-3

[8] Bruand, M., Thubert, T., Winter, N., et al. (2020) Rupture of Non-Communicating Rudimentary Horn of Uterus at 12 Weeks' Gestation. Cureus, 12, e7191. https://doi.org/10.7759/cureus.7191

[9] Hiersch, L., et al. (2015) The Association between Mullerian Anomalies and Short-Termpregnancy Outcome. The Journal of Maternal-Fetal \& Neonatal Medicine, 29, 2573-2578. https://doi.org/10.3109/14767058.2015.1098613

[10] Erez, O., Dukler, D., Novack, L., et al. (2007) Trial of Labor and Vaginal Birth after Cesarean Section in Patients with Uterine Müllerian Anomalies: A Population-Based Study. American Journal of Obstetrics and Gynecology, 196, 537.e1-537.e11. https://doi.org/10.1016/j.ajog.2007.01.012

[11] Nitzsche, B., Dwiggins, M. and Catt, S. (2017) Uterine Rupture in a Primigravid Patient with Unscarred Bicornuate Uterus at Term. Case Reports in Women's Health, 15, 1-2. https://doi.org/10.1016/j.crwh.2017.03.004

[12] Chiriboga, R. and Gonzaga-Aguilar, D. (2019) Útero didelfo, bicolis con embarazo gemelar: Revisión de la literatura a propósito de un caso. Revista chilena de obstetricia y ginecología, 84, 75-81. https://doi.org/10.4067/S0717-75262019000100075

[13] Perez, L., et al. (2007) Anomalías mullerianas Revisión. Revolution Medicines, 15, 252-253. 